\title{
Comparison of potential energy underreporting among pregnant women living in Ireland in two cohorts initiated a decade apart: the Lifeways Cross-Generation Cohort Study (2001-2003) and the Lifestyle in Pregnancy study (LIP; 2011)
}

\author{
M.M. Heinen, N. Dennehy, E. Heery, C.M. Murrin and C.C. Kelleher \\ National Nutrition Surveillance Centre, School of Public Health, Physiotherapy and Sports Science, University College \\ Dublin (UCD)
}

Diet is a significant factor in the prevention of chronic disease. In the past, misreporting of energy intake using self-reported dietary intake data has been shown to affect the interpretation of relationships between diet and disease ${ }^{(1)}$. However, the gold standard, doubly labelled water method, is expensive and not feasible in large epidemiological studies ${ }^{(2)}$. The objective of the present study was to explore whether several factors - including possible underreporting - contribute to differences observed between energy intakes among pregnant women living in Ireland in two different cohorts initiated a decade apart.

Data from two different prospective cohorts of pregnant women living in Ireland were used, the Lifeways Cross-Generation Cohort Study (initiated between Oct 2001-Jan 2003) $)^{(3)}$ and the Lifestyle in Pregnancy study (LIP; initiated in 2011) ${ }^{(4)}$. Lifeways include Irish nationals only and was representative of the general population, whilst the LIP study included about $30 \%$ foreign nationals. The same instruments and methodology used in Lifeways were applied to the LIP study. Analysis was conducted on data from a sample size of 1903 women. A validated questionnaire was used to collect biological and sociodemographic data in both cohorts. Dietary information was assessed using a Food Frequency Questionnaire ${ }^{(5)}$. Underreporting was assessed using the ratio of reported energy intake (EI) to estimated basic metabolic rate (BMR) (EI/BMR). Using the methods described by Goldberg et al. ${ }^{(6)}$, a cut-off value of $<0 \cdot 9$ was used to identify definite under-reporters and a value of $<1.2$ identified possible under-reporters. Differences between two means were assessed by Mann-Whitney U tests. For categorical variables, Chi-Square tests were performed to identify differences between proportions.

The women in the LIP study have a significantly lower energy intake compared to women in Lifeways ( $p<0 \cdot 001$; median energy intake was $2364 \mathrm{kcal}$ in Lifeways compared to $1986 \mathrm{kcal}$ in LIP study). Factors that significantly differed between the two cohorts $(\mathrm{p}<0.001)$ included the following: women in the LIP study were slightly older, higher educated and more often employed. No differences were observed for medical card possession, marital status and BMI category. Significantly more women in the LIP study were definite or potential underreporters $(29.6 \%)$ compared to women in Lifeways $(18.3 \% ; \mathrm{p}<0.001)$. Excluding non-nationals did not alter these results.

In conclusion, the observed difference in energy intake levels might be a real difference or - as our results seem to suggest - several factors might contribute to this difference, including education, age, employment and underreporting. A factor explaining the possible underreporting could differences in consenting and recruiting procedures between the two cohorts. If the difference between energy intake levels is due to underreporting, this might have implications for the designs and set-up of future studies. Future analyses will explore these factors more fully.

1. Poslusna K, Ruprich J, de Vries JHM et al. (2009) Br J Nutr 101,:S73-S85.

2. Livingstone B \& Black A (2003) Am Soc Nutr Sci 133, 8955-920S.

3. O’Mahony D, Fallon UB, Hannon F et al. (2007) Ir Med J 100,suppl 3-6.

4. Heery E, Kelleher CC, Wall PG, et al. (2015) Public Health Nutr 18, 1488-1498.

5. National Nutritional Surveillance Centre (2003) http://health.gov.ie/wp-content/uploads/2014/03/diethab.pdf (accessed April 2016).

6. Goldberg GR, Black AE, Jebb SA et al. (1991) Eur J Clin Nutr 45, 569-81. 